\title{
EDITORIAL/REDAKSIONEEL
}

\section{RECONSTRUCTION CHALLENGES TO THE SOCIAL SERVICE PROFESSIONS}

The mass media has been ever-vigilant in keeping the public informed of the extent of crime in our society. In addition to the rates at which crimes are committed, it is the nature of the crimes that is particularly horrifying. Gross abuse of children, incest, callous murder of innocent people, community traumatisation by gangs and the like have become so commonplace that we pay scant attention to the destabilising impact of these events on people and communities. These are, however, symptoms of the disintegrating social fabric and moral fibre in our society.

It is within this context that reference is made to the need for the "RDP of the soul" and why the Moral Re-generation Movement was launched.

Social service professionals provide a cadre of skilled practitioners who are able to make a significant contribution to the reconstruction of the social fabric and moral fibre in South Africa. Their intensive preparation to undertake work at individual, family and community levels equip them to initiate and sustain interventions aimed at improving people's quality of life. They have established a credible presence in communities as resource persons able to respond to felt needs.

A consistent theme in the series of provincial meetings held by the South African Council for Social Service Professions (SACSSP) throughout the country in 2001 and 2002 was the poor salaries and service conditions of practitioners. While they remain committed to the awesome task of reconstructing our society and improving the quality of life, their own professional integrity and dignity are being sorely tested through the poor salaries and unsatisfactory conditions under which they work. The morale is not very high and in one instance professionals even took to the streets in a protest march. How can the needs of people be effectively addressed if these frontline practitioners lack the basic tools of transport and telephones? How can a professional service be rendered if practitioners do not have the basic resources with which to do their work? The overwhelming caseloads associated with statutory work such as foster care investigations are debilitating to practitioners. In one instance one practitioner was expected to attend to 800 persons on her caseload. On the other hand it is underemployment of social workers when they are expected to complete applications for pensions and grants.

The salaries in the NGO sector start from as low as R3 433 per month before any deductions. In the public sector it starts at R7 046 per month. As a result there is an alarming drift from the NGO sector into the public sector, and yet some of the most creative and speedier interventions occur through the NGOs. But, even at the present level of remuneration in the public sector, the fourth year of tertiary education and training is not taken into account! Is it, therefore, surprising that some 250 workers went overseas between 1996 and 2003 ?

A meaningful increase in the total social services budget is needed. At present $88 \%$ of the 
and Foster Care Grants are paid from this budget. Service delivery and the infrastructure required for it receives at maximum $12 \%$ of the total budget. The racial equalisation of payments and the escalating number of people asserting their right to one or other form of social security payment has put great strain on the budget. The HIV/AIDS pandemic exacerbates it even further. Direct financial transfers are recognised as a decisive attack on poverty, but need to be complemented by social services that will reconstruct the social fabric and moral fibre of society. This is labour intensive work that will necessitate lifting the morale of the practitioners in the field.

In reflecting on the pre-1990 period it is significant to note how little attention was paid to preparing the social welfare sector for the post-apartheid era. In contrast to health and education, little attention was paid to this sector. During the period of the Government of National Unity the welfare portfolio was given to ministers from the previous regime. At Departmental level several Directors-General have served during the nine years since the democratic dispensation was ushered in. As a consequence the sector lagged behind others in the transition to democratic rule. Given the need for political will to place this sector at the heart of the reconstruction challenge, are we still lagging behind?

Organisation in the sector also begs questioning. Professional associations are still divided and membership extremely low. A disproportionately low percentage of the 9792 social workers, for example, belongs to professional associations. Union membership is also divided and low. It will only be through effective organisation that practitioners can raise a united voice. The South African Council for Social Service Professions, as the most representative national body of social service professionals, has by default assumed responsibility for functions that would not ordinarily be performed by a regulating body.

The SACSSP will continue its vigorous interaction with the national Department and Ministry of Social Development, the national NGOs and the Parliamentary Portfolio Committee in the interests of strengthening the capacity of social service professionals to reconstruct the social fabric and moral fibre of our society and to promote effective services being delivered to the public of South Africa.

Lionel R. Louw 